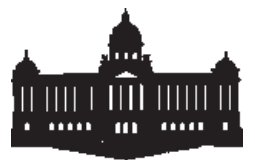

Časopis Národního muzea. Řada historická Journal of the National Museum (Prague). Series Historia $188 \cdot 3-4 \cdot 2019 \cdot($ p. $84-90)$

\title{
Jubileum Milana Ličky
}

Před krátkou dobou PhDr. Milan Lička, CSc., dlouholetý pracovník oddělení prehistorie a protohistorie, dnes oddělení pravěku a antického starověku (a jistý čas jeho vedoucí a zároveň zástupce ředitele Historického muzea) Národního muzea v Praze (NM), oslavil již jako emeritní, ale stále pracovně aktivní zaměstnanec, své osmdesátiny (naroz. 28. 3. 1939).

Jubilant po vysokoškolských studiích v Praze (FF UK, 1958-1963; k životopisným a dalším datům srv. Časopis Národního muzea 1999, roč. 168, řada historická, 94-96) působil velmi krátce jako smluvní pracovník Expozitury Archeologického ústavu ČSAV v Mostě, pak několik let v Okresním muzeu v Ústí nad Labem - Trmicích a v Oblastním muzeu v Poděbradech, aby nakonec od roku 1968 zakotvil na pozici neolitika v Národním muzeu, kterému zůstal věren až do konce své oficiální kariéry.

V souladu s obecně platnou koncepcí uplatňovanou v nejvýznamnější muzejní instituci u nás se aktivně podílel na činnostech týkajících se sbírek (např. inicioval zpracování tzv. staré sbírky, do té doby odborně takřka nevyužitelné, a převod inventárních záznamů arche-

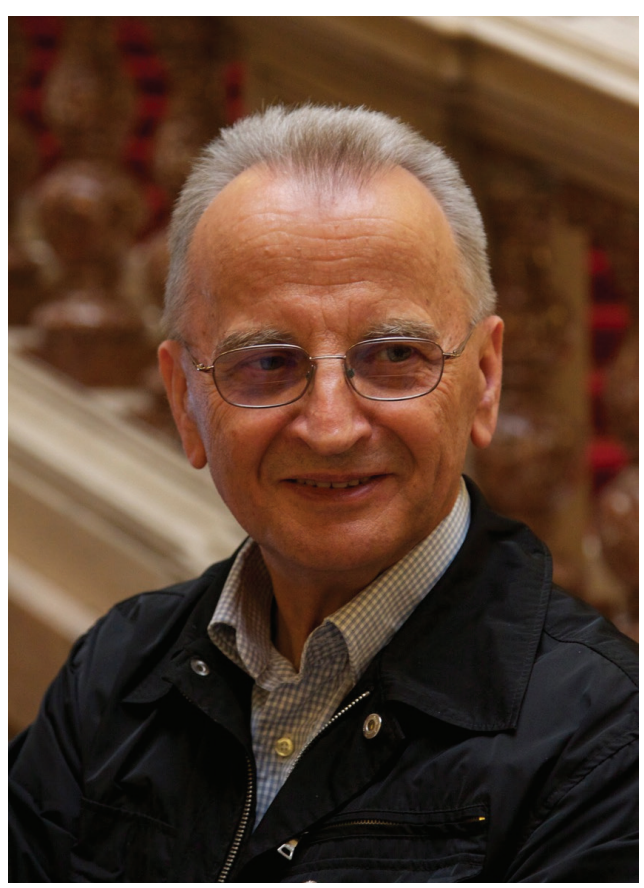
ologické sbírky do digitální podoby, dnes čítajících úctyhodných cca 420000 položek), terénních archeologických výzkumů (na polokulturní lokalitě Kosoř, Vepřek, především ale na sídlišti ve Mšeně s převahou osídlení z období kultury s vypíchanou keramikou), spoluautorských výstav v zahraničí, jmenovitě o neolitu v Itálii ve Fiorano Modenese $\mathrm{v}$ roce 2000 a Milánu v roce 2001 a 2009 a o Keltech v Itálii ve Varese v letech 2004 až 2005 a v Belgii v Morlanwelz roku 2006, které byly vždy plně hrazeny zahraničními subjekty. Stejně tak jubilant vyvíjel aktivity ve vědecké oblasti stricto sensu, napr. tím, že znalosti o keramice získával jak prostřednictvím tzv. exaktního studia, jež zahrnuje studium technologie keramiky i surovin pomocí petrografie $\mathrm{v}$ kombinaci s dalšími analytickými metodami, tak pomocí ověřo- 
vacích experimentů, případně dalších se nabízejících přístupů (napřr. daktyloskopie), a to vždy ve spolupráci s odborníky z oblasti př́rodních a technických věd. Samostatnou kapitolu z okruhu zájmu M. Ličky představuje editorská činnost, která se týkala především Fontes Archaeologici Pragenses, životně to důležitého směnného produktu Knihovny Národního muzea (pod jeho vedením, po úpadku způsobeném normalizačními poměry, se frekvence vydávání jednotlivých svazků dostala opět na dobrou úroveň).

Na závěr můžeme konstatovat, že v činnosti jubilanta se v průběhu času projevoval silný př́klon $\mathrm{k}$ aplikaci přírodovědných metod $\mathrm{v}$ archeologii (počátky tohoto trendu se projevily již v jeho nepublikované diplomové práci o raně středověké keramice z území středních Čech z roku 1963), k odpovídající prezentaci výsledků odborné i laické veřejnosti a k obsahově širokému odbornému záběru.

V posledních letech, již jako emeritní pracovník, soustavně zpracovává archeologický sbírkový fond NM a výsledky publikuje především v edici Fontes Archaeologici Pragenses. $\mathrm{K}$ této činnosti a zároveň i radosti, jakož i k jeho neutuchajícímu zájmu o cestování (Provence byla a je stále na prvním místě), mu přejeme pevné zdraví, pracovní i osobní pohodu.

(Eduard Droberjar, Martin Hložek)

\section{Bibliografie Milan LičKY}

\section{MONOGRAFIE}

Lička, M. - Lutovský, M. 2006: Vepřek und Nová Ves (Bezirk Mělník, Mittelböhmen). Ergebnisse der archäologischen Ausgrabungen zur urgeschichtlichen Besiedlung in den Jahren 1992-1995. Fontes Archaeologici Pragenses 31. Pragae.

Lička, M. 2011: Osídlení kultury s lineární keramikou v Kosoři, okr. Praha-západ - Linear Pottery Culture settlement at Kosoř, Prague-West District. Fontes Archaeologici Pragenses 37. Pragae.

Lička, M. - Švédová, J. - Šreinová, B. - Šrein, V. 2014: Makrolitické artefakty ze sídliště kultury s lineární keramikou v Kosoři u Prahy - Makrolithische Artefakte aus der linearbandkeramischen Siedlung in Kosoř bei Prag. Praha.

Lička, M. 2016: Osídlení ze starší etapy vývoje kultury s vypíchanou keramikou ve Mšeně - Besiedlung der älteren Entwicklungsetappe der Kultur mit Stichbandkeramik in Mšeno. Fontes Archaeologici Pragenses 43. Pragae.

Lička, M. 2019: Osídlení z mladší etapy vývoje kultury s vypíchanou keramikou ve Mšeně - Besiedlung der jüngeren Entwicklungsetappe der Kultur mit Stichbandkeramik in Mšeno. Fontes Archaeologici Pragenses 46. Pragae.

\section{KATALOGY K VÝSTAVÁM}

Kruta, V. - Lička, M. 2000: Prime Terrecotte dal cuore dell' Europa. Ceramiche dei cacciatori e dei primi agricoltori di Boemia e Moravia 27 000-4000 a. C. Centro Museale della Ceramica, Castello di Spezzano, Fiorano Modenese. Paris.

Kruta, V. - Lička, M. 2004: Celti, dal cuore dell'Europa all'Insubria. Celti della Boemia e Moravia. Varese.

Kruta, V. - Licka, M. - Cession-Louppe, J. 2006: Celtes: Belges, Bö̈ens, Rèmes, Volques ... Morlanwelz.

Kruta, V. - Kruta-Poppi, L. - Lička, M. - Magni, E. 2009: Antenate di Venere. 27.000-4000 a. C. Milano.

\section{ČLÁNKY A STUDIE}

Lička, M. 1966: Laténský kostrový hrob z Lysé n. L., o. Nymburk, Vlastivědný zpravodaj Polabí č. 5-6/1966, 92-93.

Lička, M. 1967: Jáma s volutovou keramikou z Rožd’alovic, okr. Nymburk - Eine Grube mit Volutenkeramik in Rožd’alovice, Krs. Nymburk, Archeologické rozhledy 19, 236-238.

Lička, M. 1967: Kostrový hrob kultury volutové z Trmic (okr. Ústí n.L.) - Ein Körpergrab der Bandkeramischen Kultur (?) aus Trmice, Krs. Ústí nad Labem, Archeologické rozhledy 19, 87-90.

Lička, M. 1968: Hradištní sekera z Nymburka, Vlastivědný zpravodaj Polabí č. 3-4/1968, 61-62. 
Lička, M. 1968: Laténský kostrový hrob z Nymburka-Zálabí - Das latènezeitliche Grab aus Nymburk-Zálabí, Archeologické rozhledy $20,353-357$.

Lička, M. - Justová, J. 1968: Železářská odpadní jáma z doby římské u Opolan (o. Nymburk) - Eine kaiserzeitliche Eisenabfallgrube aus Vinice (Kr. Nymburk), Archeologické rozhledy 20, 251-254

Lička, M. 1969: Ojedinělé slovanské nálezy z Kluku-jezera u Poděbrad - Vereinzelte slawische Funde in Kluk-jezero bei Poděbrady (Mittelböhmen), Archeologické rozhledy 21, 102-106.

Lička, M. 1969: Sklad železných předmětů pozdní doby římské z Opolan (o. Nymburk) - Ein Depotfund eiserner Gegenstände aus der späten römischen Kaiserzeit in Opolany, Kr. Nymburk, Archeologické rozhledy 21, 681-684

Lička, M. 1969: Únětické nálezy ze Mcel, Vlastivědný zpravodaj Polabí č. 1-2/1969, 19-23.

Fridrich, J. - Lička, M. 1969: Ojedinělé mladopaleolitické nálezy na Nymbursku - Vereinzelte jungpaläolithische Funde im Gebiet von Nymburk, Archeologické rozhledy 21, 95-96

Lička, M. 1970: Únětická zásobní jáma z Poříčan (okr. Nymburk), Vlastivědný zpravodaj Polabí č. 1-2/1970, 15-19.

Lička, M. 1971: Kostrový pohřeb v únětické sídlištní jámě ze Mcel (o. Nymburk). Příspěvek k poznání pohřebního ritu ve starší době bronzové - Das Skelettgrab in der Aunjetizer Siedlugsgrube von Mcely, Kr. Nymburk. Ein Beitrag zur Kenntnis des Grabbrauchs in der älteren Bronzezeit, Archeologické rozhledy 23, 669-679.

Lička, M. 1974: Použití petrografie při určování provenience prehistorické a protohistorické keramiky - L'utilisation de la petrografhie pour la détermination de l'origine de la céramique préhistorique et protohistorique, Časopis Národního muzea 143, řada historická, $188-195$.

Lička, M. 1975: Nálezy eneolitické keramiky z Loučeně (o. Nymburk), Vlastivědný zpravodaj Polabí č. 5-6/1975, 93-98.

Lička, M. - Musil, J. 1975: Určování pohlaví a věku na základě otisků papilárních linií v archeologii a kriminalistice - Československá kriminalistika 8, 185-193.

Bareš, M. - Lička, M. 1976: K exaktnímu studiu staré keramiky. K otázkám vztahu vypíchané a lengyelské kultury - The exact study of prehistoric pottery. A contribution to the problem of relations between stroke-ornamented and Lengyel pottery cultures, Sborník Národního muzea 30, řada A - Historie, 137-244.

Lička, M. - Slabina, M. 1976: Únětické a knovízské a štítarské nálezy z Poříčan (okr. Nymburk) - Aunjetizer, Knovízer und Štítary-Siedlungsfunde aus Poříčany (Bez. Nymburk), Časopis Národního muzea 145, řada historická, 125-143.

Lička, M. - Kvasnička, J. 1978: Ověření pravosti neolitické keramiky z Radimi (okr. Kolín) a Buštěhradu (okr. Kladno) termoluminiscenční metodou - Verification of the authenticity od neolithic pottery from the localities of Radim (distr. Kolín) and Buštěhrad (distr. Kladno) by the thermoluminescence method), Časopis Národního muzea 147, řada historická, 202-216.

Bareš, M. - Lička, M. 1979: Dílčí výsledky a problematika komplexního studia vybrané neolitické keramiky. In: Sborník referátů 1. celostátní konference „Aplikace geofyzikálních metod v archeologii a moderní metody terénního výzkumu a dokumentace“, Petrov nad Desnou - Brno, 145-146.

Lička, M. - Bareš, M. 1979: Antropomorfní nádoba lengyelské kultury z obj. č. VI/30 z Buštěhradu, okr. Kladno. Příspěvek k exaktnímu studiu neolitické keramiky - Das anthropomorphische Gefäss der Lengyel-Kultur aus dem Objekt Nr. VI/30 aus Buštěhrad (Bezirk Kladno). Ein Beitrag zu dem exakten Studium der neolithischen Keramik, Sborník Národního muzea 33, řada A - Historie, 69-172.

Hanáková, H. - Lička, M. 1980: Lidské pohřby na nalezišti s vypíchanou keramikou v Liběchově, okr. Mělník - Manschliche Begräbnisse an der Fundstätte mit Stichbandkeramik in Liběchov, Kreis Mělník, Časopis Národního muzea 149, řada prrírodovědná, $217-222$.

Lička, M. 1981: Hromadný nález neolitické broušené industrie (č. 1) ze Mšena, o. Mělník - Hortfund neolithischer geschliffener Steinwerkzeuge (Nr. 1) aus Mšeno, Kr. Mělník, Archeologické rozhledy 33, 607-620.

Lička, M. 1981: Neolithic settlement site at Mšeno by Mělník, Bohemia. In: J. Hrala (ed.): Archaeological news in the Czech socialist republic (Xe Congrès international des Sciences préhistoriques et protohistoriques, Mexico 1981). Praha - Brno, 24-25.

Lička, M. 1981: Žárový hrob kultury s keramikou vypíchanou z Liběchova, o. Mělník - Brandgrab der Stichbandkeramikkultur in Liběchov, Bez. Mělník, Praehistorica 8, Varia Archaeologica 2, 35-41.

Lička, M. - Bareš, M. 1981: Příspěvek k řešení vzájemného vztahu vypíchané a lengyelské kultury. Výsledky a diskuse - Con- 
tribution à l'étude des rapports entre la culture de la céramique pointilée et la culture de Lengyel. Résultats et discussion, Sborník prací filosofické fakulty brněnské university E 26, 121-140.

Bareš, M. - Lička, M. 1981: Détermination de l'origine d'un choix de céramiques néolithiques provenant de diverses localités tchécoslovaques dans le cadre d'un programme d'études d'ensemble de la céramique ancienne. Résultats, Revue d'Archéometrie 5 - Supplément III (Actes du XX Symposium international d'Archéometrie), 9-17.

Bareš, M. - Lička, M. - Růžičková, M. 1981: K technologii neolitické keramiky I - On the technology of neolithic pottery I, Sborník Národního muzea 35, řada A - Historie, 1981, 137-227.

Bareš, M. - Lička, M. - Růžičková, M. 1982: K technologii neolitické keramiky II - On the technology of neolithic pottery II, Sborník Národního muzea 36, řada A, 121-237.

Lička, M. - Slabina, M. 1986: Pravěké osídlení Mcel (okr. Nymburk) a jejich okolí - Die urzeitliche Besiedlung von Mcely (Bez. Nymburk) und ihre Umgebung, Časopis Národního muzea 155, řada historická, 109-139.

Lička, M. 1988: A Programme of experimental kiln firings in Czechoslovakia, Bulletin of Experimental Archaeology 9 (Southampton), 11-14.

Lička, M. 1988: Mšeno (okres Mělník) a jeho okolí v pravěku - Mšeno (Kreis Mělník) und seine Umgebung in der Urzeit, Časopis Národního muzea 157, řada historická, 1-20.

Lička, M. - Slabina, M. 1989: K otázce použití anorganického hnojiva v pravěku - Zur Frage der Anwendung anorganischer Dünger in der Vorzeit, Archeologické rozhledy 41, 406-413.

Lička, M. 1990: Grundrisse von Doppelhäusern (?) aus Stichbandkeramik. In: Sborník Bylany Seminar 1987, Praha, $227-231$.

Lička, M. 1990: Osídlení kultury s vypíchanou keramikou ve Mšeně u Mělníka, část I - Besiedlung der Kultur mit Stichbandkeramik in Mšeno bei Mělník, Teil I, - Sborník Národního muzea 44, řada A - Historie, 1-84.

Lička, M. - Koštuřík, P. - Mach, Z. 1990: Hrnčířská pec lengyelské kultury z Kramolína (okr. Třebíč). K otázce výskytu zařízení k výpalu keramiky ve starším úseku pravěku - Töpferofen der Lengyel-Kultur aus Kramolín (Kreis Třebíč). Zur Frage des Vorkommens der Produktionsanlage zum Keramikbrennen im älteren Abschnitt der Urgeschichte, Časopis Národního muzea 159, řada historická, 1-20.

Lička, M. 1991: Résultats d'expériences relatives à la cuisson de la céramique préhistorique dans différents types de structures cuisson et de fours. In: Archéologie Expérimentale I, T. 1 -

Le feu: le métal, la céramique. Actes du Colloque International „Expérimentation en archéologie: Bilan et Perspectives, l'Archéodrome de Beaune les 6, 7, 8 et 9 avril 1980. Paris 203-209.

Lička, M. 1991: Výzkum technologie výroby neolitické keramiky prostřednictvím experimentu - Erforschung der Produktionstechnologie der neolithischen Keramik durch Experimente, Časopis Národního muzea 160, řada historická, 1-10.

Lička, M. - Mach, Z. 1992: Experimentální výpal keramiky v replice pravěké hrnčířské pece - Experimenteller Keramikbrand in der Rekonstruktion eines urgeschichtlichen Töpferofenes, Časopis Národního muzea 161, r̆ada A, 65-78.

Lička, M. 1993: Mladší doba kamenná - neolitické sídliště. In: K. Sklenář - M. Lutovský (red.): Vepřek - archeologický výzkum na Kralupsku. Kralupy nad Vltavou, 16-18.

Lička, M. - Bareš, M. 1993: Technologie de la céramiques néolithique: méthodes et problèmes des recherches. In: Pulpudeva 6 Semaines philippopolitaines de l'histoire et de la culture thrace. Sofia, 90-104.

Lička, M. 1994: Zu Töpferöfen der Lengyel-Kultur. In: Internationales Symposium über die Lengyel-Kultur 1888-1988, Znojmo - Kravsko - Těšetice, Brno - Łódż, 192-199. Lička, M. - Mach, Z. 1999: Erläuterung zu den Ergebnissen der mikroskopischen Analyse und der Röntgen-Diffraktionanalyse der Proben der Keramik aus Dobřichov-Pičhora. In: Droberjar, E.: Dobřichov-Pičhora. Ein Brandgräberfeld der älteren römischen Kaiserzeit in Böhmen (Ein Beitrag zur Kenntnis des Marbod-Reichs), Fontes Archaeologicici Pragenses 12, Pragae, 201-202.

Lička, M. - Přichystal, A. - Sklenář, K. - Šreinová, B. - Beneš, J. 1999: Př́íspěvek k osídlení kultury s keramikou vypíchanou v Horkách nad Jizerou, okr. Mladá Boleslav - Ein Beitrag zur Besiedlung der Kultur mit Stichbandkeramik in Horky nad Jizerou, Bezirk Mladá Boleslav, Časopis Národního muzea 168, řada historická, 1-22.

Lička, M. - Tempír, Z. 1999: Příspěvek k neolitickému osídlení Kosoře, okr. Praha-západ - Beitrag zur neolithischen Besiedlung den Gemeinde Kosoř, Bezirk Praha-západ, Sborník prací filozofické fakulty brněnské univerzity M 4, 31-39. 
Lička, M. 2000: Jáma neobvyklého tvaru na sídlišti kultury s vypíchanou keramikou ve Mšeně, okr. Mělník - Eine Grube von ungewöhnlicher Form auf der Siedlung der Kultur mit Stichbandkeramik in Mšeno, Bezirk Mělník, Časopis Národního muzea 164, řada historická, č. 3-4, 1-11.

Lička, M. 2002: Soubor zlatých předmětů mladší doby bronzové z neznámého naleziště v Čechách - Jungbronzezeitlicher Fundkomplex von Goldobjekten aus unbekanntem Fundort in Böhmen, Časopis Národního muzea 171, řada historická, 1-16.

Lička, M. 2004: Vznik digitální databáze archeologické sbírky Oddělení prehistorie a protohistorie Národního muzea a její zpř́istupnění veřejnosti, Muzejní a vlastivědná práce 42 / Časopis společnosti přátel starožitnosti 112, 107-112.

Lička, M. 2004: Žárové hroby kultury s vypíchanou keramikou, pozdní doby halštatské a časné doby laténské ze Mšena, okr. Mělník - Brandgräber der Stichbandkeramik-Kultur, der späten Hallstattzeit und frühen Letène-Zeit von Mšeno, Bez. Mělník. In: E. Kazdová - Z. Měř́nský - K. Šabatová (editoři): K poctě Vladimíru Podborskému. Brno, 71-87.

Lička, M. - Fridrich, J. 2004: Paleolitická kamenná industrie z Lipí, okr. České Budějovice. Časopis Národního muzea 173, řada historická, $1-7$.

Lička, M. 2006: Stopy osídlení ze starší doby hradištní v Kosoři, okr. Praha-západ - Settlement traces from the Early Slavic period at Kosoř, district Praha-západ. In: Vita Archaeologica - Sborník Víta Vokolka. Hradec Králové - Pardubice, 153-167.

Lička, M. 2009-2010: Otvory ve stěnách nádob kultury s lineární keramikou v Kosoři, okr. Praha-západ - Öffnungen in der Wandung von Gefässen der Kultur mit Linearbandkeramik in Kosoř, Bez. Prag-West, Sborník prací filozofické fakulty brněnské univerzity M 14-15, 131-148.

Lička, M. - Hložek, M. 2011: Antropomorfní soška kultury s lineární keramikou z Chabařovic, okr. Ústí nad Labe - Anthropomorphic statuette of the Linear Pottery culture from Chabařovice, Ústí nad Labem District, Archeologie ve středních Čechách 15 , 35-49.

Lička, M. 2012: K otázce interpretace zahloubených objektů uvnitř pozdnělengyelského domu z Postoloprt, okr. Louny - On the problem of how to explain sunken features inside a late Lengyel house from Postoloprty, Louny District, Archeologie ve středních Čechách 16, 623-648.

Lička, M. - Mach, Z. 2013: Mazanicový sídlištní odpad jako zdroj informací o neolitických jednokomorových pecích - Daub Debris at Settlement Sites as a Source of Information for Neolithic Ovens. In: I. Cheben - M. Soják (eds.): Otázky neolitu s eneolitu našich krajín - 2010. Nitra, 153-172.

Lička, M. 2018: Drobné keramické artefakty ze sídliště kultury s vypíchanou keramikou ve Mšeně, okr. Mělník - Small ceramic artefacts from Stroked Pottery culture settlement in Mšeno (Mělník District), Archeologie ve středních Čechách 22, 589-593.

Lička, M. 2019: Houses from Mšeno (Central Bohemia) in the context of the development of the Stroked Pottery Culture. Anthropologie (Brno) 57/3, 271-286.

Lička, M. 2019: Nádoby zvláštního významu ze sídliště kultury s vypíchanou keramikou ve Mšeně (okr. Mělník) - Special-purpose ceramic vessels from a settlement of Stroked Pottery Culture in Mšeno (Mělník District), Archeologie ve středních Čechách $23,95-112$.

\section{DROBNÉ ZPRÁVY A VĚDECKO-POPULÁRNÍ ČLÁNKY}

Lička, M. 1967: Zaniklé osady a tvrze, Vlastivědný zpravodaj Polabí č. 1-2/1967, 11-12.

Lička, M. 1968: Přehled př́růstků archeologických nálezů za rok 1966, Vlastivědný zpravodaj Polabí č. 1-2/1968, 27-28.

Lička, M. 1969: Z nových archeologických nálezů Poděbradského muzea (r. 1967), Vlastivědný zpravodaj Polabí č. 1-2/1969, $25-27$.

Lička, M. 1970: Znovuobjevené pravěké sídliště, Nové Mělnicko 19, č. 23, 3.

Lička, M. 1971: Stopy krve v pravěké keramice, Vesmír, č. 11, 126.

Lička, M. 1974: Spodografie v archeologii, Věda a život 10, 614.

Lička, M. 1975: Nález lidské kostry v Liběchově, Liběchovský zpravodaj, červen-červenec, 5-6.

Lička, M. 1980: XXème symposium international d'archéometrie (Paris 26.-29.3.1980), Archeologické rozhledy 32, 571.

Lička, M. 1987: Zemřel Miroslav Bareš, Archeologické rozhledy 39, 462.

Lička, M. 1988: Ajn Ghazel - sídliště z počátku neolitu, Věda a život 33, 425-426. 
Lička, M. 1988: Archeodrom v Burgundsku, Věda a život 33, 866-869.

Lička, M. 1988: Co ukázal výzkum, Nové Mělnicko 27, 37.

Lička, M. 1989: Doklady kanibalismu z jeskyně Fontbrégoua, Věda a život 34, 49-50.

Lička, M. 1989: Nejstarší čínský drak, Věda a život 7, 47-48.

Lička, M. 1989: Nejstarší hrnčířská pec ve střední Evropě, Věda a život 34, 53-54.

Lička, M. 1990: O pravěkém zemědělství, Věda a život 35, 18.

Lička, M. 1991: Muzejní expozice v Pincevent u Montereau, Francie, Časopis Národního muzea 160, řada historická, 99-101.

Lička, M. 1991: Na okraj jednoho kolokvia, Časopis Národního muzea 160, řada historická, 95-96.

Lička, M. 1996: K hromadnému nálezu železných nástrojů z keltského oppida u Stradonic, okr. Beroun, Muzejní a vlastivědná práce 34,174-175.

Lička, M. 1996: Úmrtí PhDr. Jiř́ho Břeně, CSc., Archeologické rozhledy 48, 525-526.

Lička, M. - Slabina, M. 1996: Výstava „Kult Kraft Kosmos - bronze Symbols in central Europe and Scandinavia“ a symposium „Central Europe and south Scandinavia in the Bronze Age“, Archeologické rozhledy 48, 523-524.

Lička, M. 1998: Oddělení prehistorie a protohistorie. In: E. Paulová (ed.): Z pokladnice Národního muzea 1818-1998, Praha $16-17$.

Lička, M. 1998: PhDr. Karel Sklenář, DrSc., šedesátiletý, Časopis Národního muzea 167, řada historická, č. 3-4, 69-70.

Lička, M. 1998: Tresaures of celtic art: a European heritage, Archeologické rozhledy 50, 700-701.

Lička, M. 1998: Životní jubileum Karla Sklenáře, Archeologické rozhledy 50, 703-705.

Lička, M. 1999: Ostrov dávných věků, Muzejní a vlastivědná práce 37/Časopis společnosti přátel starožitností 107, $249-250$.

Lička, M. 2000: L'or des princes barbares. Du Caucas à la Gaule au Ve siècle après J.-C., Archeologické rozhledy 52, 726-727.

Lička, M. 2000: Oddělení prehistorie a protohistorie. In: Muzejní průvodce. Národní muzeum - Historické muzeum. Praha, $11-20$.

Lička, M. 2000: Výstava „Prime Terrecotte dal cuore dell'Europa. Ceramiche dei cacciatori e dei primi agricoltori di Boemia e Moravia 27 000-4000 a.C., Archeologické rozhledy 52I, 549.

Lička, M. 2001: Langobardi v Itálii, Muzejní a vlastivědná práce 39, 180-181.

Lička, M. 2002: Celtas y Vettones, Archeologické rozhledy 54, 331.

Lička, M. 2002: Tajemství skythského a sarmatského lidu, Muzejní a vlastivědná práce 40, 39-40.

Lička, M. 2002: Nové muzeum pravěku ve Francii, Muzejní a vlastivědná práce 40/ Časopis společnosti přátel starožitností 110, 173-174.

Lička, M. 2002: Výstava Keltové a Vettoni, Muzejní a vlastivědná práce 40, 40-41.

Lička, M. 2002: Výstava o italské moderní keramice v Praze, Muzejní a vlastivědná práce 40/Časopis společnosti přátel starožitností 110,173 .

Lička, M. 2003: Jubileum edice Fontes Archaeologici Pragenses, Muzejní a vlastivědná práce 41/Časopis společnosti přátel starožitností 111, 189-191.

Lička, M. 2003: Zpřístupnění databáze archeologické sbírky Oddělení prehistorie a protohistorie Národního muzea, Věstník AMG/2003, 3-4.

Lička, M. 2003: Zpřístupnění dvou počítačových databází Oddělení prehistorie a protohistorie Národního muzea v Praze, Archeologické rozhledy 55,633 .

Lička, M. - Slunečko, V. 2004: Databáze archeologické sbírky Národního muzea a internet. Věstník AMG 4, 5.

Lička, M. - Slunečko, V. 2004: Internetová databáze archeologické sbírky Oddělení prehistorie a protohistorie Národního muzea v Praze. Archeologické rozhledy 56, 417.

Lička, M. 2006: Celtes. Belges, Boïens, Rémes, Volques... Archeologické rozhledy 58, 355-356.

Humpolová, A. - Lička, M. 2009: Výstava o českém neolitu v Itálii, Archeologické rozhledy 61, 756-757. 


\section{EDITORSKÁ ČINNOST}

Lička, M. 1997-2007: Fontes Archaeologici Pragenses 20-33 (celkem 16 svazků)

Lička, M. 1997: Ilustrovaný průvodce pravěkem 1. Praha, Národní muzeum.

Karasová, Z. - Lička, M. 2002: Sborník Národního muzea, řada A - Historie

56 (Figuration et abstraction dans l'art de l'Europe ancienne [VIIIème-Ier s. av. J.-C.]. Actes du Colloque international de Prague, Musée National, 13.-16. Juillet 2000).

Referáty o knihách nejsou uvedeny (celkem 68 položek) 